\title{
Mechanical stability of a salt cavern submitted to high-frequency cycles
}

\author{
B. Brouard \\ Brouard Consulting, Paris, France \\ P. Bérest \& H. Djizanne \\ LMS, Ecole Polytechnique Paris Tech, Palaiseau, France
}

\author{
A. Frangi \\ Politecnico di Milano, Milano, Italy
}

\begin{abstract}
Storage of natural gas in salt caverns had been developed mainly for seasonal storage, resulting in a small number of yearly pressure cycles and moderate gas-production rates. The needs of energy traders are changing toward more aggressive operational modes. Gas temperature changes and additional stresses generated by high-frequency cycling in a storage cavern are discussed. It is proved that when fast pressure changes or short-period gas pressure cycles are considered, the thickness of the thermally disturbed zone at the cavern wall is relatively small. Refined meshes of the disturbed zone are required when performing numerical computations.
\end{abstract}

\section{INTRODUCTION}

Gas storage caverns were developed mainly for seasonal storage, with one or a few cycles per year and a moderate gas-production rate between the maximum and minimum operation pressures. Gas typically is injected in the summer and withdrawn in winter when demand is higher. However, the needs of energy traders are changing toward more aggressive operating modes, with large swings to take advantage of buying and storing natural gas during low-demand periods (at low cost) to remove and sell it during high-demand periods (at a higher price). This implies faster flow rates and shorter recovery periods. This operation mode also is considered for Compressed Air Storage (CAES) facilities.

Cavern stability must be assessed when highfrequency cycles are performed. Numerical computations raise specific problems. Temperature changes can be dramatic in a thin layer at a cavern wall. Stresses experience rapid changes in this thin layer. Time steps and sizes of the mesh elements must be selected carefully in order to prevent numerical inaccuracies. In this context, a comparison between numerical computations and closed-form solutions is helpful. In Section 2, the case of a periodic gas temperature is considered. In Section 3, the elastic (instantaneous) stresses generated by rapid temperature changes are discussed. In Section 4, the energy balance equation is established and some simplifications allow for closed-form solutions, which can be compared to numerical computations. In Section 5, failure criteria are discussed briefly, and in Section
6, examples of numerical computations are presented.

\section{TIME AND SPACE SCALES}

\subsection{Rule of thumb}

When performing numerical computations including fast pressure changes or high-frequency cyclic loading, the following spatial and time scales should be considered.

- Spatial scale: the thermally disturbed zone must contain at least several mesh elements in the radial direction. A well-adapted radial size $\Delta x_{\max }$ for the largest elements is:

$\Delta x_{\max }=\Delta r / 10$

Where $\Delta r=$ thickness of the thermally disturbed zone. Mesh elements should not be larger than $\Delta x_{\max }$ in the direction perpendicular to the cavern wall.

- Time scale: the size $\Delta x_{\max }$ of the largest element at the cavern wall must be small and the maximum time step of the numerical computations, $\Delta t_{\max }$, should be consistent. The time step must be such that

$$
\Delta t_{\max }<\Delta x_{\max }^{2} / n k_{\text {salt }}
$$


where $n=4$ (resp. $n=6$ ) for 2D (resp. 3D) computations.

\subsection{Temperature cycling}

As an example, the following simplified problem is considered: cavern gas temperature is a sinusoidal function of time.

$$
T(t)=\bar{T}+\Delta T \sin (\omega t) \quad \omega=2 \pi / \tau
$$

where $T=$ average gas temperature, $\Delta T=$ amplitude of the temperature cycle, $\omega=$ pulsation and $\tau=$ cycle period.

Lestringant et al. (2010) gave the stationary temperature distribution in the rock mass as a function of radius, $r$, and time, $t$, in the case of an idealized spherical cavern.

$$
\begin{aligned}
T_{\text {salt }}(r, t)= & \bar{T}+\Delta T_{\text {salt }}(r, t) \\
\Delta T_{\text {salt }}(r, t)= & \left(\frac{a}{r}\right) \Delta T \exp \left[-(r-a) \sqrt{\omega / 2 k_{\text {salt }}}\right] \\
& \times \sin \left[\omega t-(r-a) \sqrt{\omega / 2 k_{\text {salt }}}\right]
\end{aligned}
$$

where $a=$ cavern radius, and $k_{\text {salt }}=$ salt thermal diffusivity ( $k_{\text {salt }}=3 \times 10^{-6} \mathrm{~m}^{2} / \mathrm{s}$ is typical. )

Figure 1 shows, when $\tau=1$ day, $\bar{T}=10^{\circ} \mathrm{C}$ and $\Delta T=10^{\circ} \mathrm{C}$, the temperature radial distribution at the vicinity of the cavern wall when gas temperature reaches its maximum. Lestringant et al.'s closedform solution is compared to finite-elements computations performed using LOCAS software (Brouard et al., 2006). The above-mentioned rules of thumb were respected. The stationary distribution associated with the closed-form solution is reached after a few cycles and the thickness of the thermally disturbed zone is approximately $\Delta r \approx 1.8 \mathrm{~m}$; it is practically independent of cavern radius when this radius is larger than $10 \mathrm{~m}$.

Figure 2 shows the radial temperature distribution for a cylindrical cavern when gas temperature is minimal in the case of sinusoidal thermal loading when cycling period is one day. As expected, the thickness of the disturbed zone is similar to that in the case of a smaller spherical cavern.

Figure 3 shows the radial temperature distribution for a spherical cavern when gas temperature is minimal in the case of a non-sinusoidal thermal loading when cycling period is one day. The temperature distribution is similar to that in the case of a sinusoidal cycle; in particular, temperature still reaches a peak at a distance $\Delta r^{\prime} \approx \Delta r / 3$ from cavern wall.

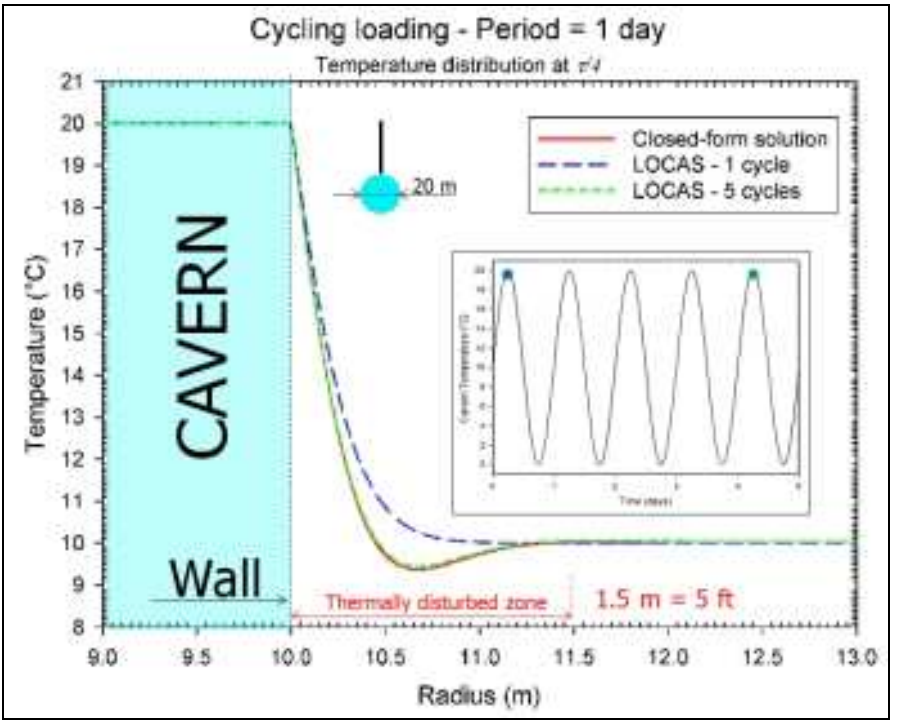

Figure 1. Spherical cavern: radial temperature distribution at the vicinity of the cavern wall when gas temperature reaches its maximum value. Comparison between a finite-elements code (LOCAS) and a closed-form solution.

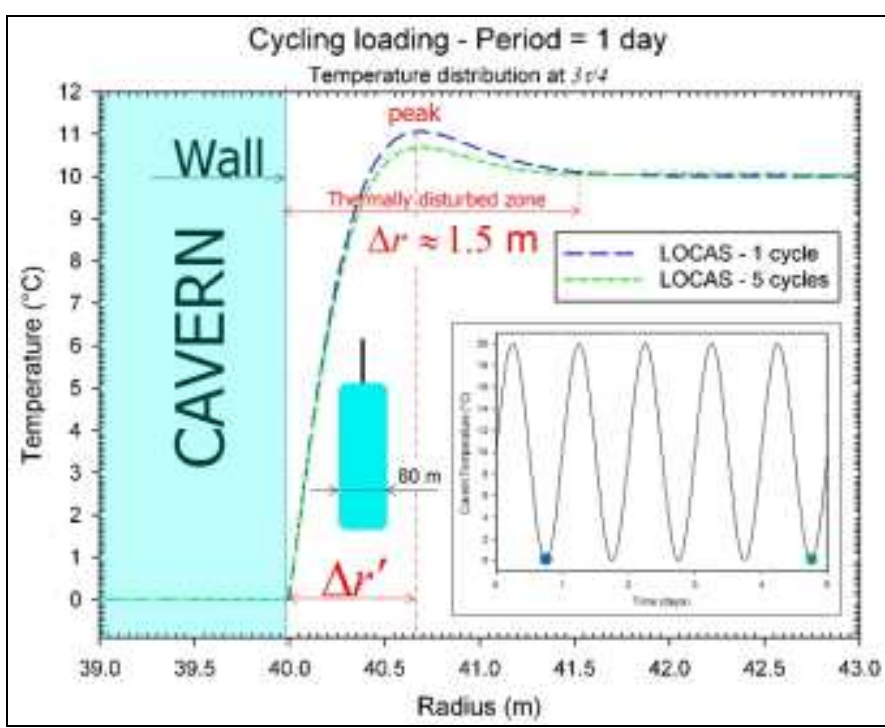

Figure 2. Cylindrical cavern: radial temperature distribution when gas temperature reaches its minimal value.

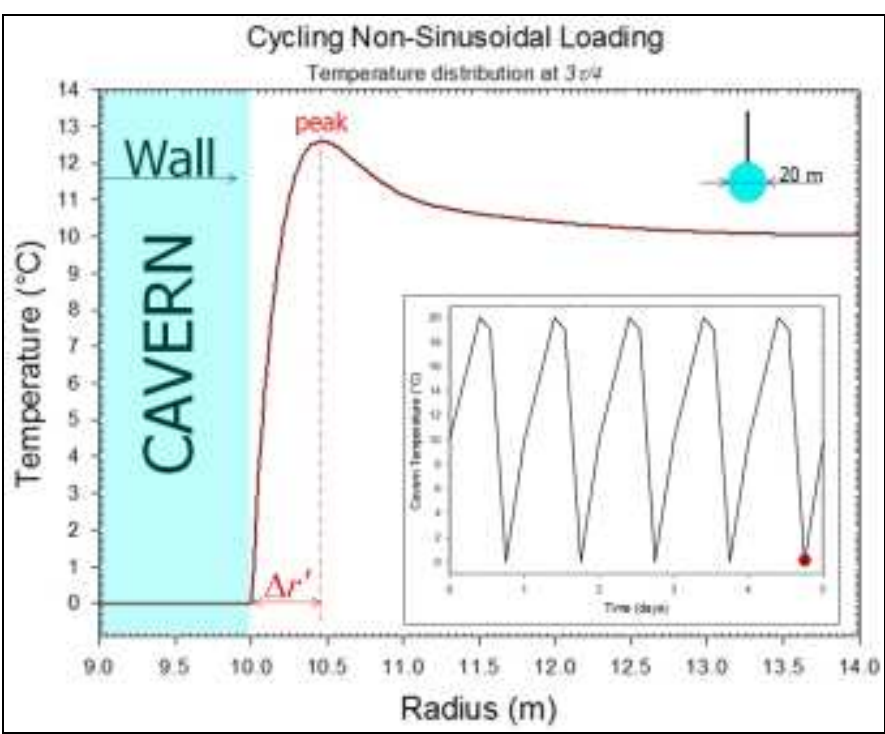

Figure 3. Small spherical cavern: radial temperature distribution at the vicinity of the cavern wall, non-sinusoidal cycling. 


\subsection{Effect of cycling period}

The effect of the cycling period on temperature distribution in the rock mass is illustrated in Figure 4. LOCAS software was used. Cavern temperature was cycled over three different periods: one day, one week and one month. The radial temperature distribution is plotted after five cycles when gas temperature and pressure are lowest. As can be inferred from the closed-form solution (5), the size of the disturbed zone increases with cycle period, or $\tau$. Furthermore, even when this period is relatively large, a temperature peak still can be observed. From formula (5) it can be inferred that, in this case, the thickness, $\Delta r^{\prime}$, of the disturbed zone from cavern wall to location of the temperature peak is a function of the cycling period which can be expressed as:

$$
\Delta r^{\prime} \approx 290 \sqrt{\pi k_{\text {salt }} \tau / 2}
$$

where $\Delta r^{\prime}$ is in $\mathrm{m}$, salt thermal diffusivity, $k_{\text {salt }}$, in $\mathrm{m}^{2} / \mathrm{s}$, and cycling period, $\tau$, in days.

According to formulas (1), (2) and (6), $\Delta t_{\max }$, the time step to be used for 2D computations, is a linear function of the cycling period:

$$
\Delta t_{\max }<\Delta r^{2} / 100 k_{\text {salt }}=\pi \tau / 200
$$

For instance, the maximum time step for 2D numerical computations and daily cycling should be $\Delta t_{\text {max }}<\pi / 200$ day $\approx 23 \mathrm{~min}$

From these computations it can be inferred that the thermally disturbed zone at the vicinity of a cavern submitted to daily pressure/temperature changes remains thin, even when the cavern is large (dimensional analysis proves that thickness of the thermally-disturbed zone is practically independent of cavern radius). Furthermore, as large thermo-elastic stresses are triggered by temperature/pressure variations (see below), a very fine mesh of this disturbed zone is mandatory when finite-element or finitedifference computations are to be performed.

\section{THERMOELASTICITY}

\subsection{Introduction}

Salt-temperature variations, $\Delta T_{\text {salt }}$, induced by cavern-pressure cycling, generate additional thermoelastic stresses whose order of magnitude is $E_{\text {salt }} \alpha_{\text {salt }}$. Reasonable values of $E_{\text {salt }}$ and $\alpha_{\text {salt }}$ lead to $E_{\text {salt }} \alpha_{\text {salt }} \approx 1 \mathrm{MPa} /{ }^{\circ} \mathrm{C}$ : thermoelastic stresses have a dramatic influence on stress distribution in a thin zone at the cavern wall and they must be computed accurately. Closed-form solutions exist when simple shapes are considered. Table 1 gives additional stresses due to temperature variation, $\Delta T_{\text {salt }}(r)$, in the salt.

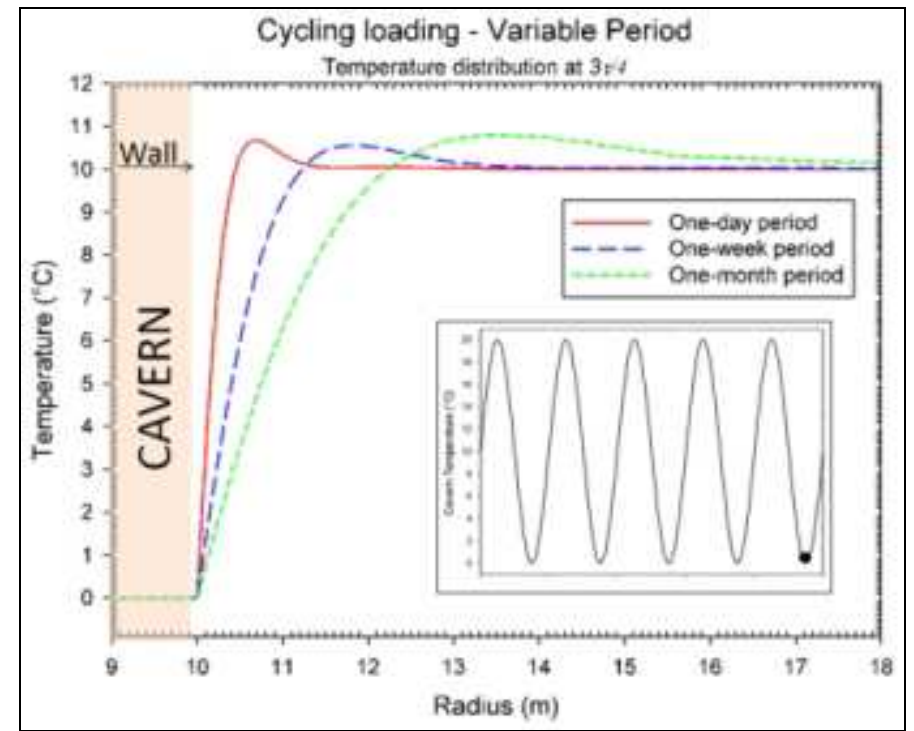

Figure 4. Small spherical cavern: radial temperature distribution at the vicinity of the cavern wall, effect of cycling period.

\begin{tabular}{|c|c|c|c|}
\hline \multicolumn{2}{|c|}{ Additional stress } & $\begin{array}{l}\text { Spherical } \\
\text { shape }\end{array}$ & $\begin{array}{l}\text { Cylindrical } \\
\text { shape }\end{array}$ \\
\hline Radial & $\Delta \sigma_{r r}(r)$ & $-\frac{2 \varpi}{r^{3}} I(r)$ & $-\left(\frac{a}{r}\right)^{2} \varpi J(r)$ \\
\hline Tangential & $\Delta \sigma_{\theta \theta}(r)$ & $\begin{array}{l}+\frac{\varpi}{r^{3}} I(r) \\
-\varpi \Delta T_{\text {salt }}(r)\end{array}$ & $\begin{array}{l}+\frac{\varpi}{r^{3}} I(r) \\
-\varpi \Delta T_{\text {salt }}(r)\end{array}$ \\
\hline Vertical & $\Delta \sigma_{z z}(r)$ & $-\varpi \Delta T_{\text {salt }}(r)$ & $-\varpi \Delta T_{\text {salt }}(r)$ \\
\hline
\end{tabular}

Table 1. Thermoelastic additional stresses for simple shapes.

where $\varpi=E_{\text {salt }} \alpha_{\text {salt }} /\left(1-v_{\text {salt }}\right),\left(E_{\text {salt }}, v_{\text {salt }}\right)=$ salt elastic parameters, $\alpha_{\text {salt }}=$ coefficient of thermal expansion of salt and $I(r)$ and $J(r)$ are integrals defined as follows:

$$
I(r)=\int_{a}^{r} u^{2} \Delta T_{\text {salt }}(u) d u \quad J(r)=\int_{a}^{r} u \Delta T_{\text {salt }}(u) d u
$$

\section{ENERGY BALANCE}

A differential equation for energy balance in a gas cavern was first established in ATG (1986):

$$
m C_{v} \dot{T}-V T\left(\frac{\partial P}{\partial T}\right)_{\rho} \dot{\rho}=\langle\dot{m}\rangle C_{p}\left(T_{e}-T\right)+q_{c}
$$

where $P, T, m, \rho, V$ are gas pressure, temperature, mass, density and volume, respectively. $C_{p}$ and $C_{v}$ are gas heat capacities, $r=C_{p}-C_{v} . T_{e}$ is the temperature of the injected gas; $\langle\dot{m}\rangle=\dot{m}$ when $\dot{m}>0$ (gas injection) and $\langle\dot{m}\rangle=0$ when $\dot{m}<0$ (gas withdrawal). The left-hand side of (9) is the 
derivative of the gas internal energy minus the power of the external forces; the right-hand side is the flux of enthalpy originating in gas injection plus the heat flux $q_{c}$ from the rock mass through the cavern walls:

$q_{c}=\int_{\partial \Omega}-K_{\text {salt }} \frac{\partial T_{\text {salt }}}{\partial n} d a$

where $K_{\text {salt }} \approx 6 \mathrm{~W} / \mathrm{m}-\mathrm{K}=$ salt thermal conductivity.

Temperature evolution in the rock mass is governed by heat conduction:

$\frac{\partial T}{\partial t}=k_{\text {salt }} \Delta T$

where $k_{\text {salt }} \approx 3 \times 10^{-6} \mathrm{~m}^{2} / \mathrm{s}=$ salt thermal diffusivity.

This equation must be completed by the gas equation of state:

$$
P V=\operatorname{mrTZ}(P, T)
$$

where $Z=Z(P, T)$ is a corrective factor (« compressibility factor $\gg)$.

Cavern closure rate can be written as:

$$
\dot{V} / V=\beta_{c} \dot{P}+\dot{\varepsilon}^{v p}
$$

where $\beta_{c}$ is the "hole-in-the-salt» coefficient of compressibility, which depends on cavern shape and elastic properties of the rock mass; $\dot{\varepsilon}^{v p}$ is the cavern viscoplastic closure rate, which depends on rock mass constitutive behavior, cavern shape, cavern pressure history and rock mass temperature.

This full set of equations, (9) to (14), must be solved when performing numerical computations. However, a couple of simplifications allow capturing the main features of temperature evolution and provides closed-form solutions, which are used to check the accuracy of numerical computations:

1. $Z(P, T)=1$ is an acceptable approximation; however, it is more accurate for air than for natural gas.

2. In (14), the coefficient of compressibility, or $\beta_{c} \approx 1-210^{-4} / \mathrm{MPa}$, is small when compared to gas compressibility, or $1 / P ; \dot{\varepsilon}^{v p}$, or cavern creep closure, is slow in a not-too-deep cavern. When these quantities are neglected, cavern volume is constant, $V=V_{0}$ and $m=\rho V_{0}$.

Equation (9) takes the simple form:

$$
m C_{v} \dot{T}-r T \dot{m}=\langle\dot{m}\rangle C_{p}\left(T_{e}-T\right)+q_{c}
$$

- During a standstill, $\dot{m}=0$, no gas is injected or withdrawn from the cavern, and temperature evolution can be described by the following equation:

$m C_{v} \dot{T}=q_{c}$

Fluid temperature changes are much faster than in a brine-filled cavern (because $\left.m C_{v}\right|_{\text {gas }}$ is much smaller than $\left.m C_{v}\right|_{\text {brine }}$ ), and faster still when gas mass (and pressure) are small.

- During gas withdrawal, $\dot{m}<0,(9)$ can be written:

$$
m C_{v} \dot{T}-r T \dot{m}=q_{c}
$$

Should gas withdrawal be extremely fast, the right-hand side of (17) could be neglected; temperature evolution would be adiabatic $\left(\mathrm{Tm}^{r / C_{v}}=\right.$ cste $)$. However, in an actual cavern, gas withdrawal is not fast enough to be adiabatic; when gas withdrawal is slow enough, pressure drops down first, but may increase at the end of the withdrawal phase, as observed by Crotogino et al. (2001) during an air withdrawal at the Huntorf CAES.

- During gas injection, $\dot{m}>0,(9)$ can be rewritten:

$$
m C_{v} \dot{T}=\dot{m}\left(C_{p} T_{e}-C_{v} T\right)+q_{c}
$$

And here again, when gas injection is extremely fast, $q_{c}$ can be neglected:

$$
m=m_{0}\left(C_{p} T_{e}-C_{v} T_{0}\right) /\left(C_{p} T_{e}-C_{v} T\right)
$$

where $m_{0}$ and $T_{0}$ are gas mass and temperature when gas injection starts.

These closed-form solutions can be used to check numerical computations accuracy.

- After many cycles, when heat flux $q_{c}$ can be neglected (a somewhat unrealistic assumption), gas temperature tends to asymptotic values:

$$
\left\{\begin{array}{l}
T_{\max }^{\infty}=\gamma T_{e}\left(1-K^{1 / \gamma}\right) /(1-K) \\
T_{\min }^{\infty}=\gamma T_{e}\left(K^{1-1 / \gamma}-K\right) /(1-K)
\end{array}\right.
$$

where $\gamma=C_{p} / C_{v}$ and $K=P_{\min } / P_{\max }$ is the ratio between minimum and maximum gas pressures.

and the following cases can be considered: 


\section{STABILITY — FAILURE CRITERIA}

When dealing with fast pressure changes, cycling loading and cavern stability, the onset of tensile stresses and salt dilation at the cavern wall must be discussed.

\subsection{Tension criterion}

When tensile stresses develop at cavern wall, there is a risk of salt fracturing and spalling. The following two criteria can be considered.

- No Tension - This criterion stipulates that no main stress must be tensile:

$\sigma_{\max }<0$

where $\sigma_{\max }$ is the least compressive of the three principal stresses.

- No tensile effective stress at cavern wall - This criterion stipulates that the effective tangential stresses $\sigma_{\text {eff }}$ at cavern wall must be negative:

$$
\sigma_{e f f}=\sigma_{t t}+P<0
$$

where $\sigma_{t t}$ is the less compressive tangential stress. This criterion is much more demanding than the "No-tension" criterion. It is not met when a gasfilled cavern is submitted to a fast and large pressure increase. It must be noted that the relevance of this criterion (Brouard et al., 2007) has not been investigated fully yet.

\subsection{Dilation criterion}

When shear stresses are large enough (when compared to the mean stress) salt micro-fracturing and dilation take place. These lead to an increase in permeability and a loss of rock strength. Various criteria were suggested in the literature, see Figures 18 and 19.

\section{NATURAL-GAS-STORAGE LOADING SCENARIO}

\subsection{Numerical computations}

Numerical computations were performed using LOCAS software (Brouard et al., 2006), which allows computation of fully coupled gas thermodynamical and rock thermo-mechanical evolutions.

\subsection{Considered cavern}

A $560,000 \mathrm{~m}^{3}$ axisymmetric gas-filled cavern is considered. The top of the cavern is at a 1350-m depth, cavern shape is cylindrical and it is $300 \mathrm{~m}$ high. The mesh used for numerical computations is shown on Figure 5. The number of elements is 13,988 and their size at cavern wall is $20 \mathrm{~cm}$. Geostatic pressure is applied at the right boundary of the mesh at a 600$\mathrm{m}$ distance from cavern axis.

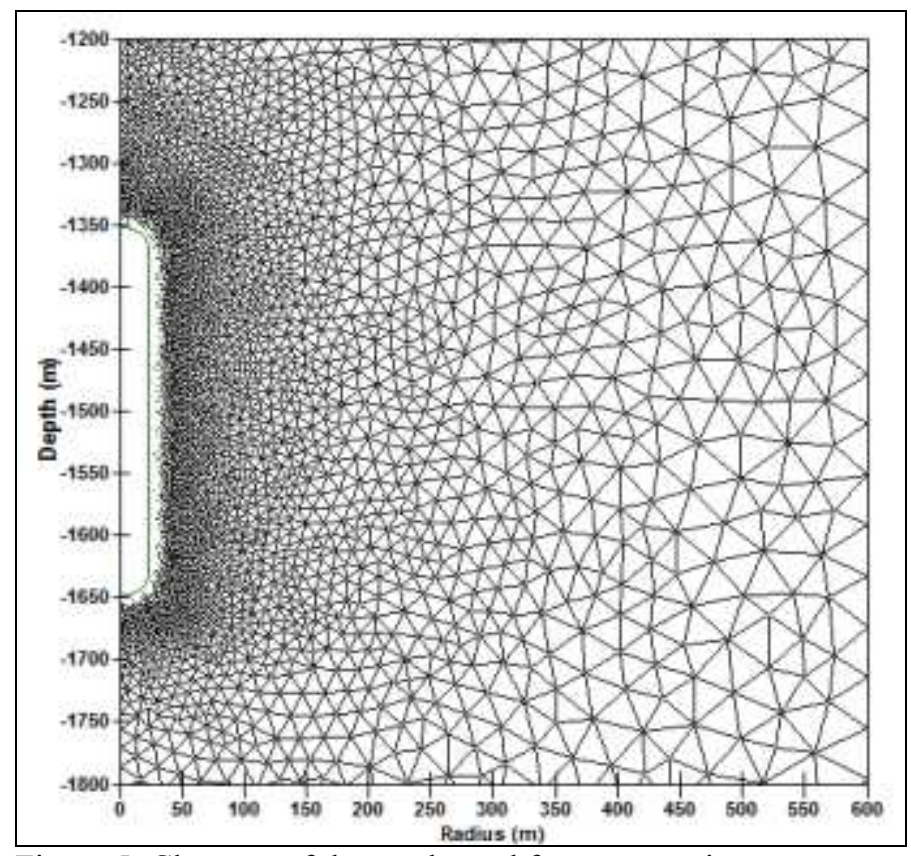

Figure 5. Close-up of the mesh used for computations.

\subsection{Salt properties}

Munson \&Dawson (1984) constitutive law was selected to describe salt behavior. Creep parameters are given in Table 2. Steady-state parameters $(A, n$, $Q / R)$ are those of Etrez salt (Bérest et al., 2001); transient creep parameters were given by Munson (1999) for Avery Island salt.

Table 2. Considered Munson-Dawson creep parameters.

\begin{tabular}{|l|l|l|}
\hline \multicolumn{2}{|l|}{ Parameters } & \multicolumn{2}{l|}{ Units } & \multicolumn{1}{l|}{ Value } \\
\hline$A$ & $\mathrm{MPa}^{\mathrm{n}}-\mathrm{yr}$ & 0.64 \\
$Q / R$ & - & 3.1 \\
$m$ & $\mathrm{~K}$ & 4100 \\
$\alpha_{w}$ & - & 3 \\
$\beta_{w}$ & - & -13.2 \\
$K_{0}$ & $/ \mathrm{MPa}^{\mathrm{m}}-\mathrm{yr}$ & $7 \times 10^{-7}$ \\
$\delta$ & - & 0.58 \\
$c$ & $/ \mathrm{K}$ & 0.00902 \\
\hline
\end{tabular}




\subsection{Cavern loading}

The considered evolution of cavern pressure is shown on Figure 6. Cavern leaching duration is 700 days; leaching is followed by a 50 -day long period during which cavern pressure remains halmostatic. Cavern debrining is 250-day long. At the end of debrining the cavern is filled with gas whose pressure is $23 \mathrm{MPa}$. From that moment the cavern is submitted to both seasonal and micro-cycling pressure variations for 10 years. Every year the cavern experiences a 70-day long pressure drop from 23 to $8 \mathrm{MPa}$, then the pressure is kept around minimum pressure during 90 days, it is followed by a 70-day long pressure increase from 8 to $23 \mathrm{MPa}$. The pressure then is kept around maximum pressure during 135 days.

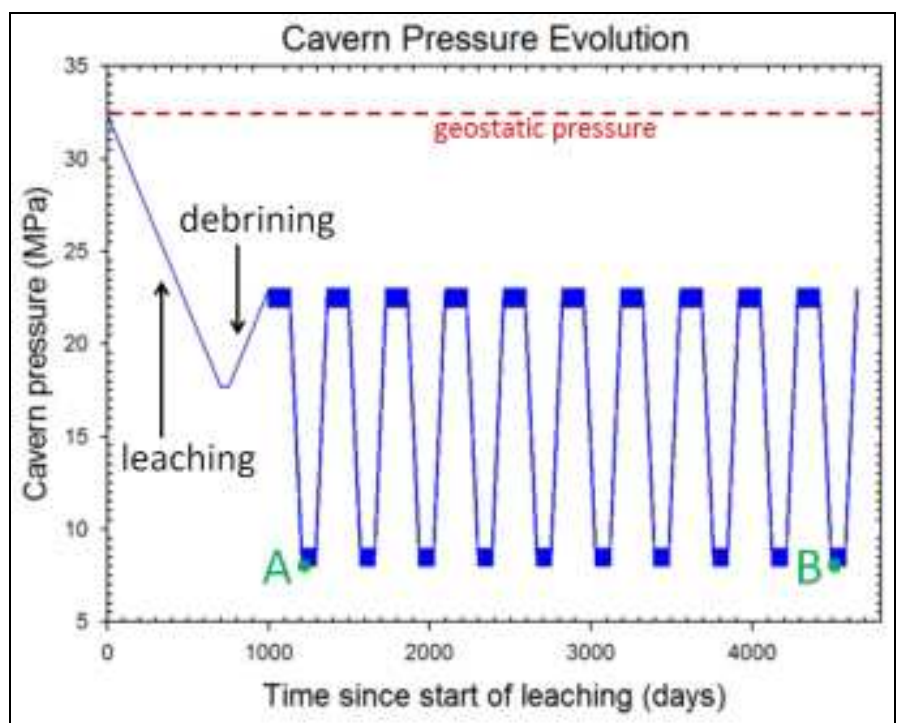

Figure 6. Evolution of cavern pressure.

As displayed in Table 3, two scenarios are considered for micro-cycling variations. In both cases, cavern pressure is increased and decreased daily by $\pm 0.5 \mathrm{MPa}$. Withdrawal and compression operations are of the same durations in scenario \#1. Withdrawal is much faster than compression in scenario \#2. Figure 7 shows a comparison between the two scenarios in the vicinity of the first pressure minimum (point A). According to the rules explained in Section 2.1, a maximum time step of 0.02 day $(30 \mathrm{~min})$ is applied during cycling.

Table 3. Characteristics of the two micro-cycling scenarios.

\begin{tabular}{|c|c|c|}
\hline & Scenario \#1 & Scenario \#2 \\
\hline $\begin{array}{l}\text { Withdrawal duration } \\
\text { (hours) }\end{array}$ & 12 & 3 \\
\hline $\begin{array}{l}\text { Withdrawal rate } \\
\text { (MPa/day) }\end{array}$ & 2 & 8 \\
\hline $\begin{array}{l}\text { Compression duration } \\
\text { (hours) }\end{array}$ & 12 & 21 \\
\hline $\begin{array}{l}\text { Compression rate } \\
(\mathrm{MPa} / \text { day) }\end{array}$ & 2 & 1.1 \\
\hline
\end{tabular}

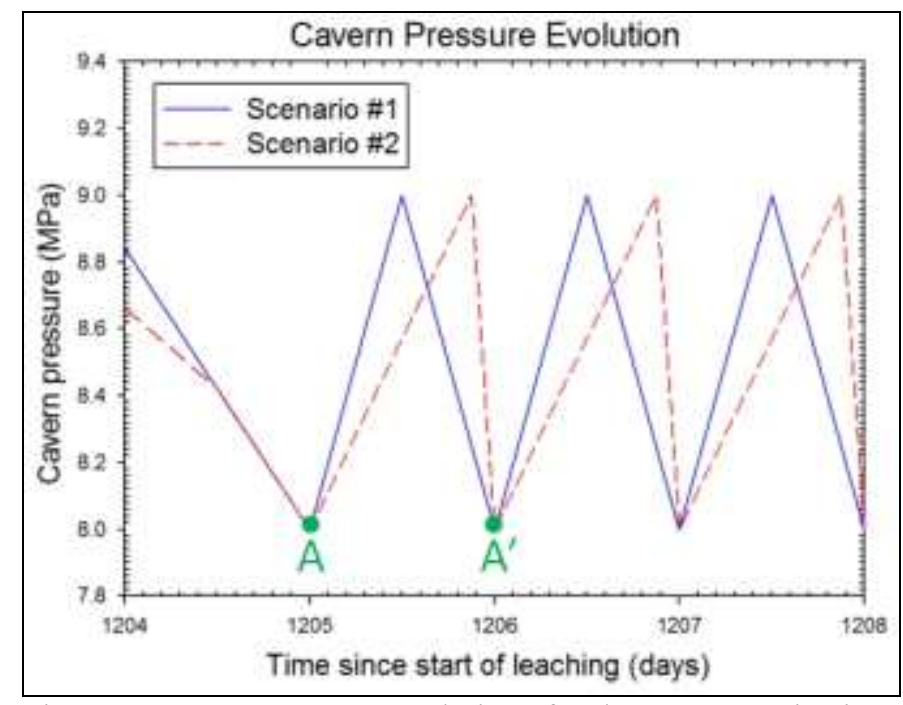

Figure 7. Cavern pressure evolutions for the two scenarios in the vicinity of the first minimal pressure period.

\subsection{Computations results}

Figure 8 shows the evolution of cavern volume during cycling. Volume variations are the same for both scenarios. Volume loss is approximately $7 \%$ after 10 years.

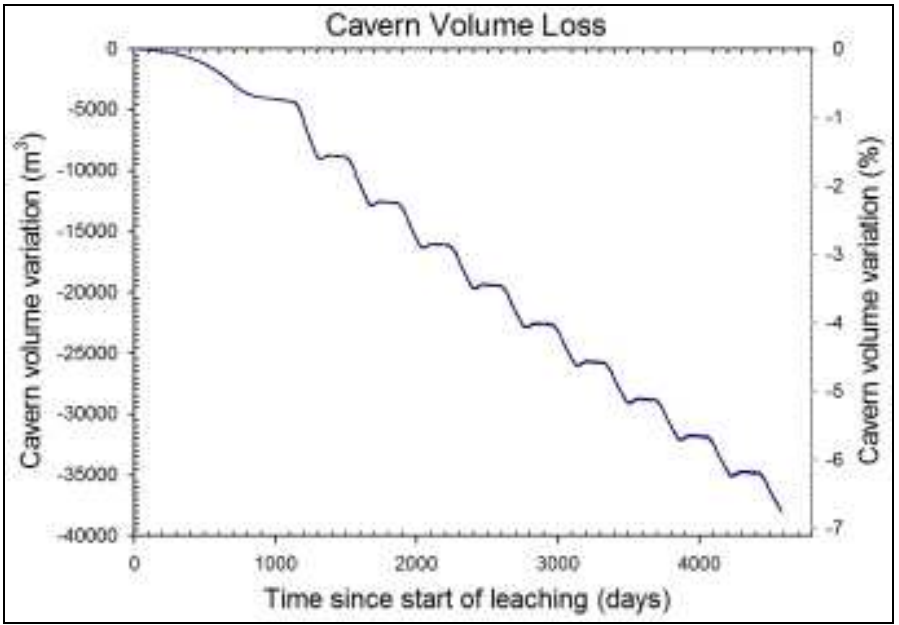

Figure 8. Evolution of cavern volume during cycling.

Computed evolution of cavern gas temperature is shown in Figure 9. Over the long term, cavern average temperature decreases and tends to move toward a temperature slightly warmer than the temperature of the injected gas $\left(40^{\circ} \mathrm{C}\right)$.

Figure 10 and 11 show the evolution of gas temperature when cavern pressure is lowest at the beginning of the first and last cycles. Minimum temperatures are very close for both scenarios, which means that the heat flux from the rock mass is small. Figure 12 shows radial distribution of temperature at a 1550-m depth for both scenarios during the first and second pressure minimums of the first cycle. 


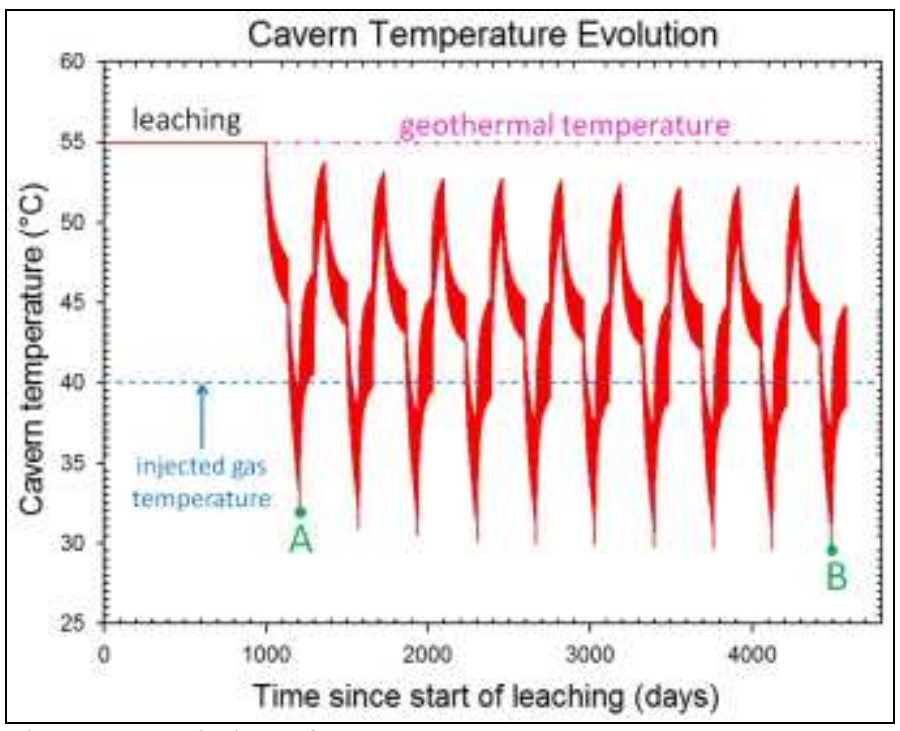

Figure 9. Evolution of gas temperature.

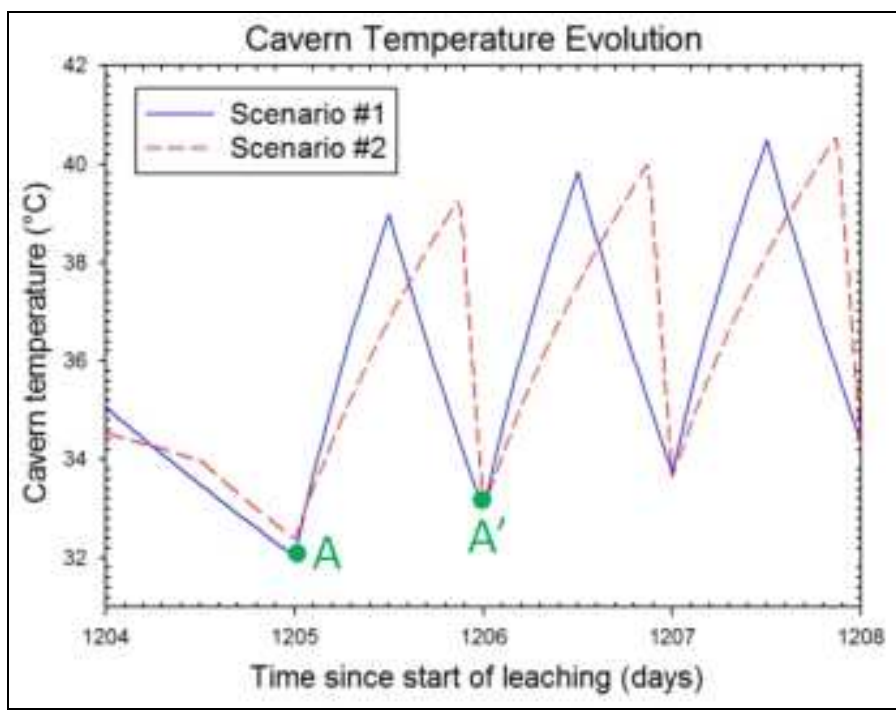

Figure 10. Evolution of gas temperature at first pressure minimums during first seasonal cycle.

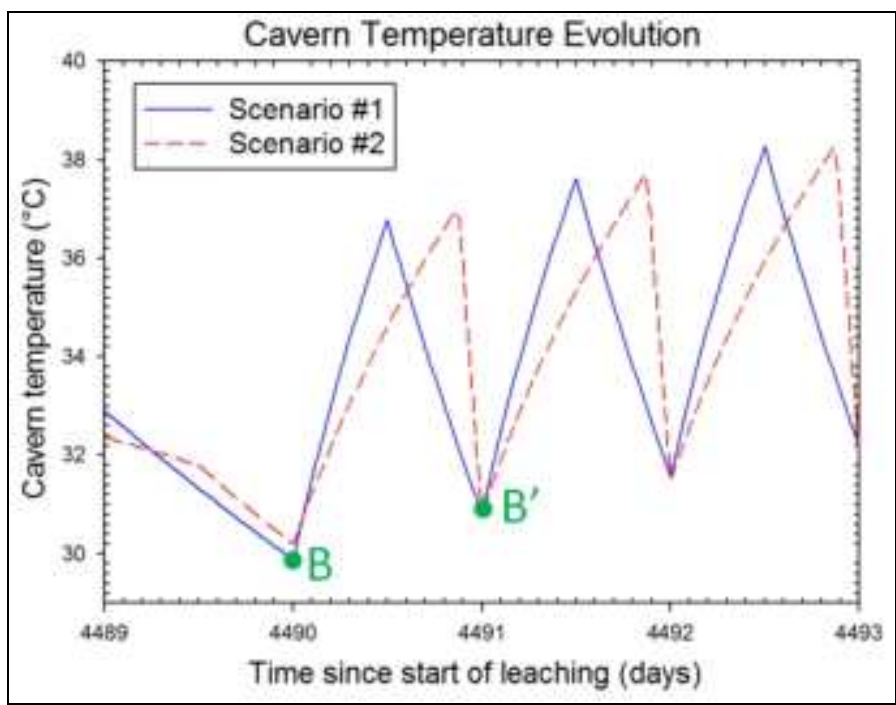

Figure 11. Evolution of gas temperature around pressure minimum during last seasonal cycle.

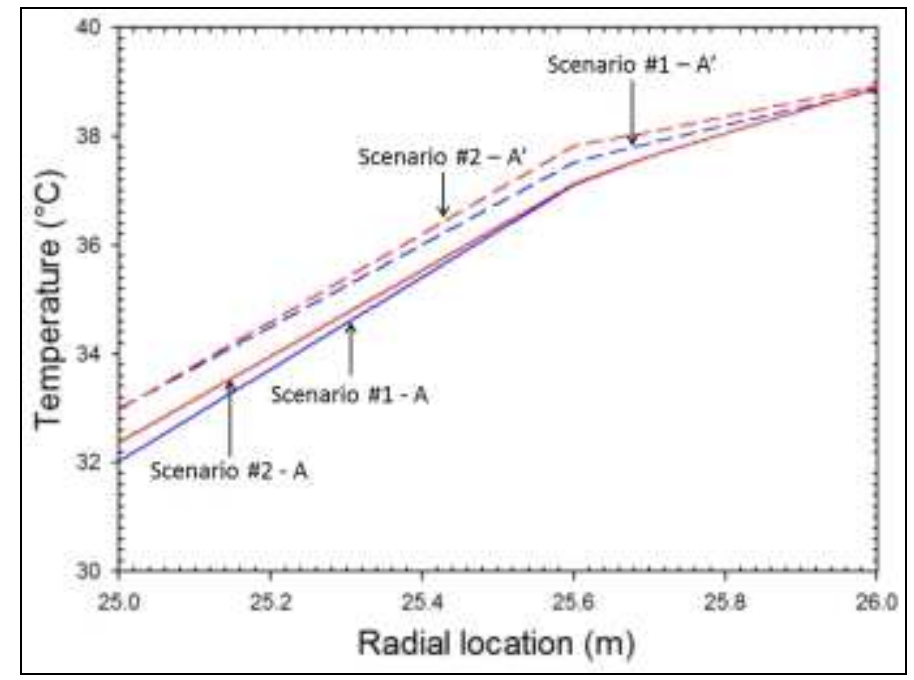

Figure 12. Radial distribution of salt temperature for both scenarios at first and second pressure minimum during first seasonal cycle.

Maximum principal stress in the vicinity of the cavern at first and second pressure minimum (points A and A' on Fig. 7) are shown in Figure 13 and 14, respectively. In both cases, there are no tensile stresses at cavern wall, even if, after a rapid pressure drop, $\sigma_{\max }$ is slightly less compressive. Yearly and daily pressure drops are too slow and too small, respectively, to generate large tensile stresses.

Contour plot of dilation Factor of Safety at second pressure minimum (point A') is given in Figure 15. DeVries dilation criterion and Cayuta salt parameters (DeVries, 2006) were considered. The thickness of the dilation zone $(\mathrm{FOS}<1)$ is in the order of cavern radius $(25 \mathrm{~m})$.

Figure 16 shows radial distribution of effective stress at a 1550-m depth for both scenarios at first, and second pressure minimums during the first seasonal cycle. There is no tensile effective stress at the first pressure minimum (A), but tensile effective stresses appear at the second pressure minimum (A') and the thicknesses of the tensile zone are $19 \mathrm{~cm}$ and $33 \mathrm{~cm}$ in scenario \#1 and \#2, respectively. Figure 16 shows the same distribution for the last cycle.

In Figure 18 and 19, the path followed by the state of stresses in the invariants plane during the 10-year long cycling period is represented together with four dilation criteria, the Spiers (1988), Ratigan (1991) criteria and the two DeVries (2006) criteria for compression and extension, respectively. Parameters given by DeVries (2006) for Cayuta salt are considered. The state of stress is computed at cavern wall, at a $1550-\mathrm{m}$ depth, a location which can be considered as representative of the mechanical behavior of the cavern main body. When Spiers or Ratigan criteria are considered, no dilatancy occurs during cycling, proving that results are extremely sensitive to the selected dilation criterion. 


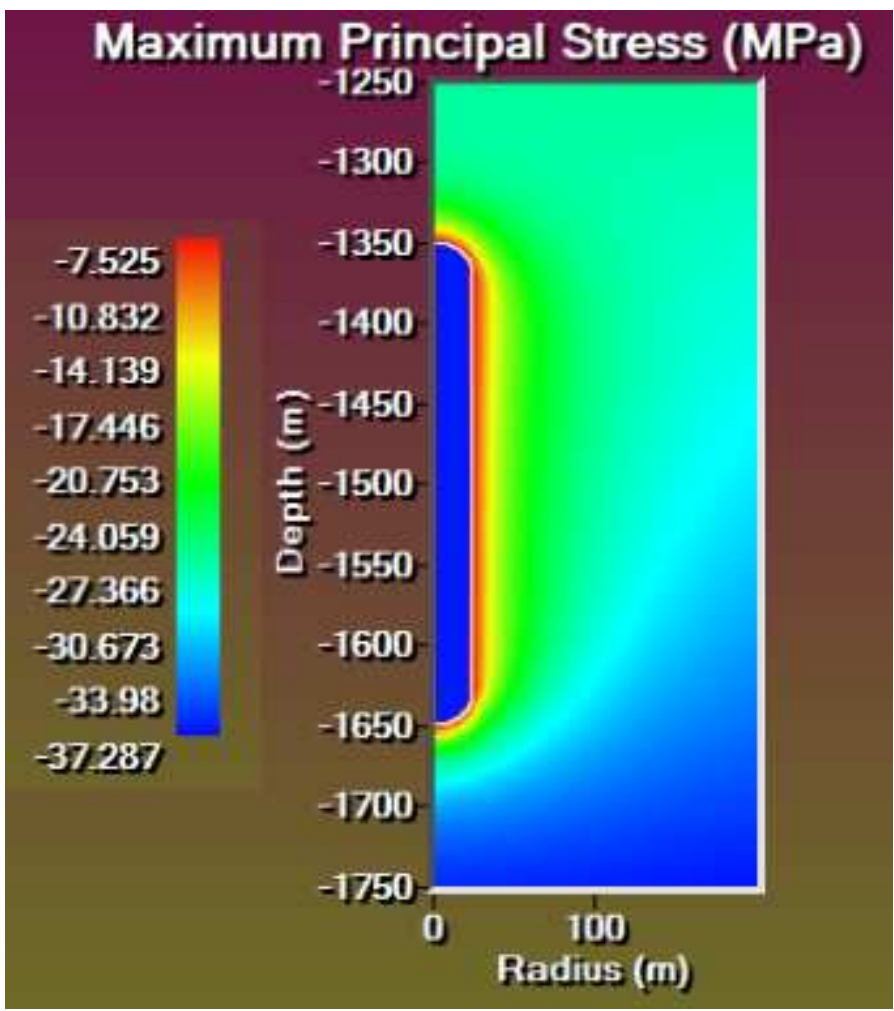

Figure 13. Scenario \#2 - Maximum principal stress $\sigma_{\max }$ (least compressive) at first pressure minimum during first seasonal cycle (point A).

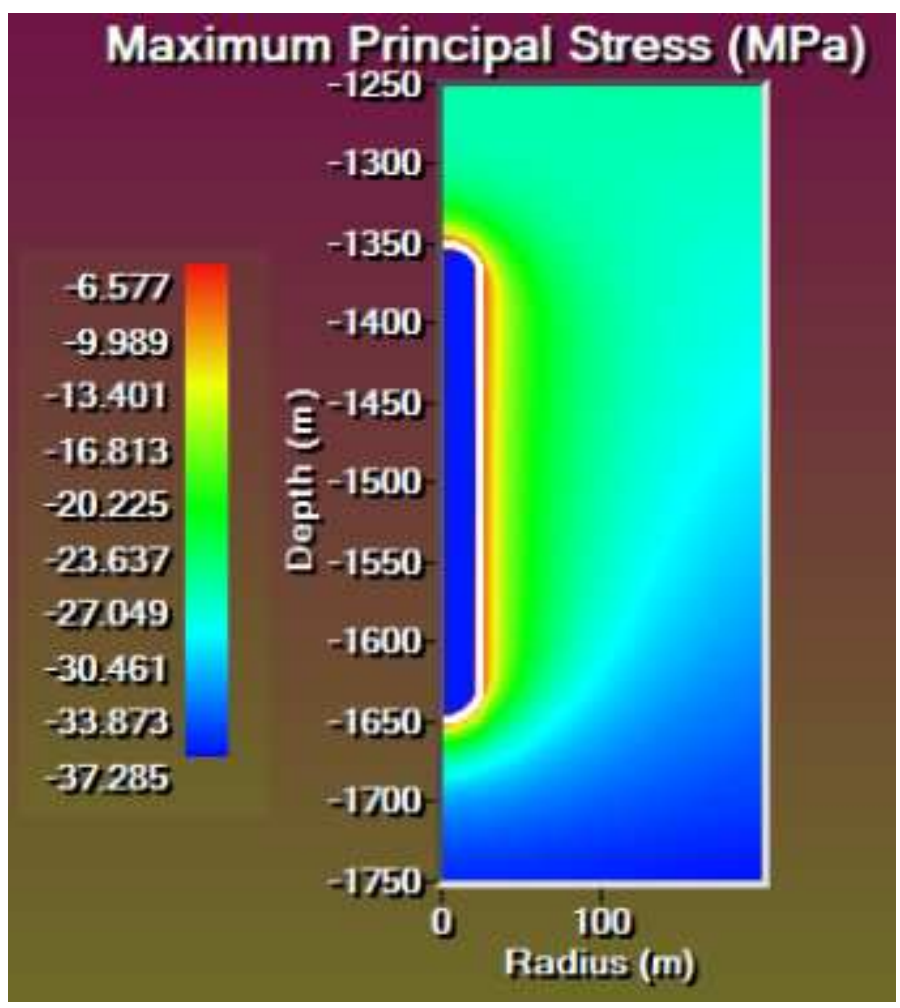

Figure 14. Scenario \#2 - Maximum principal stress $\sigma_{\max }$ (least compressive) at second pressure minimum during first seasonal cycle (point A').

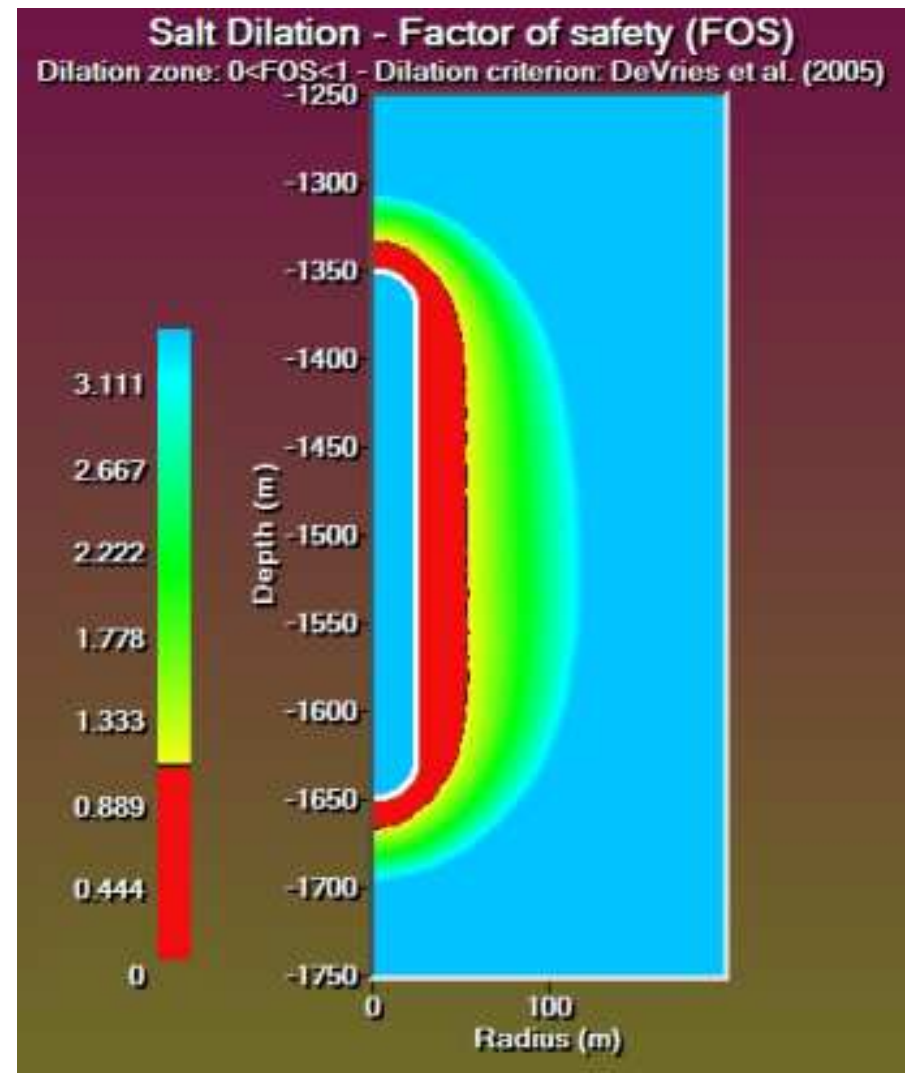

Figure 15. Scenario \#2 - Factor of Safety for dilation at second pressure minimum during first seasonal cycle (point A').

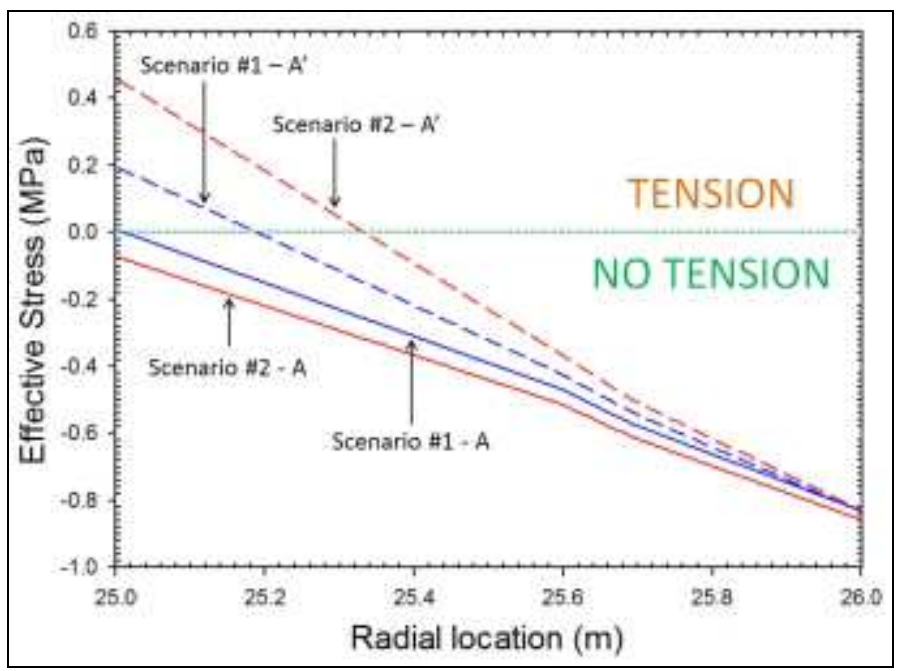

Figure 16. Radial distribution of effective stress for scenarios $\# 1$ and \#2 at first and second pressure minimums during the first seasonal cycle. 


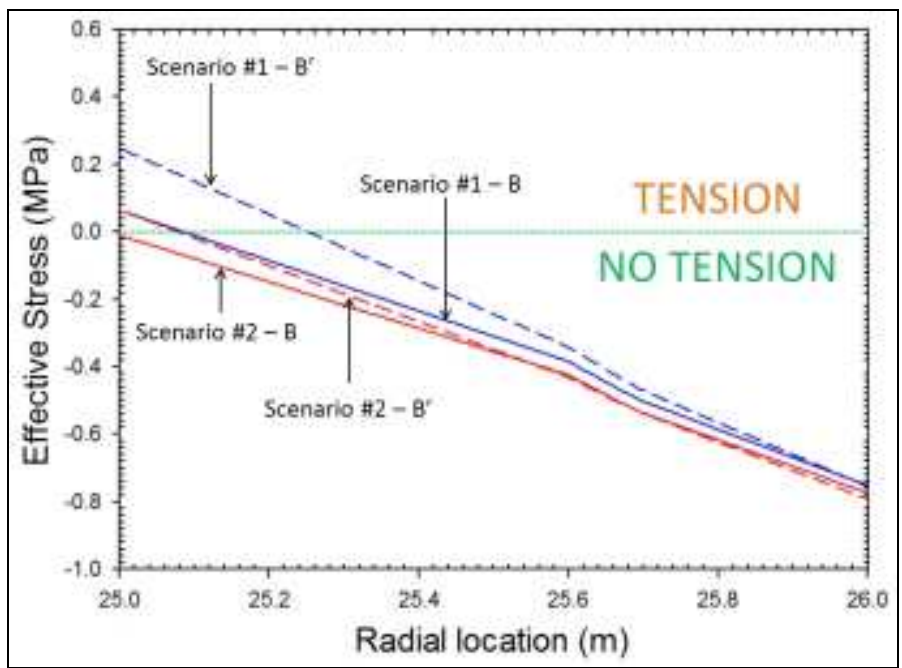

Figure 17. Radial distribution of effective stress for scenarios $\# 1$ and \#2 at first and second pressure minimums during the last seasonal cycle.

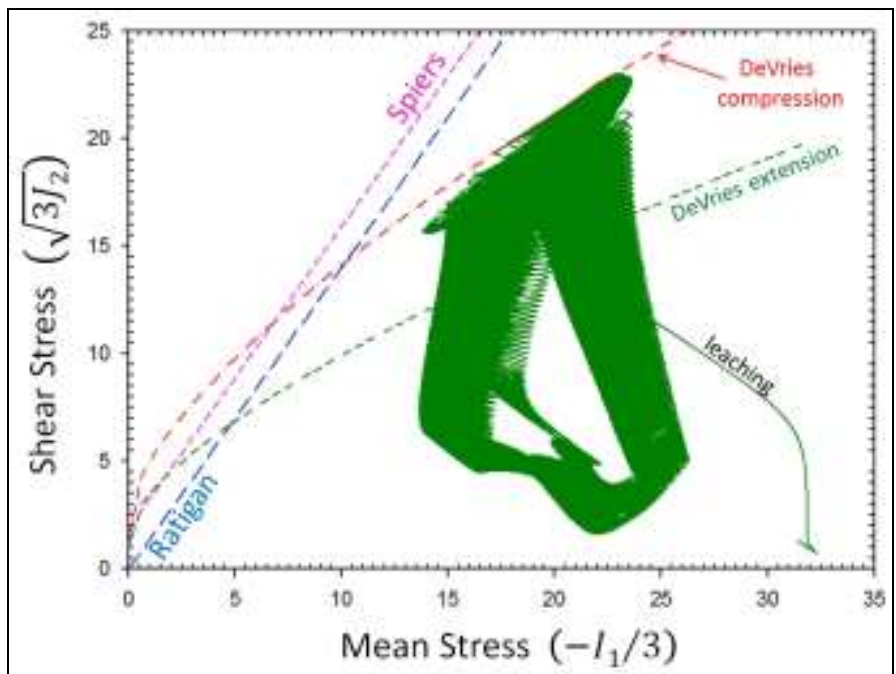

Figure 18. Scenario \#1 - Evolution of the state of stress in the invariants plane.

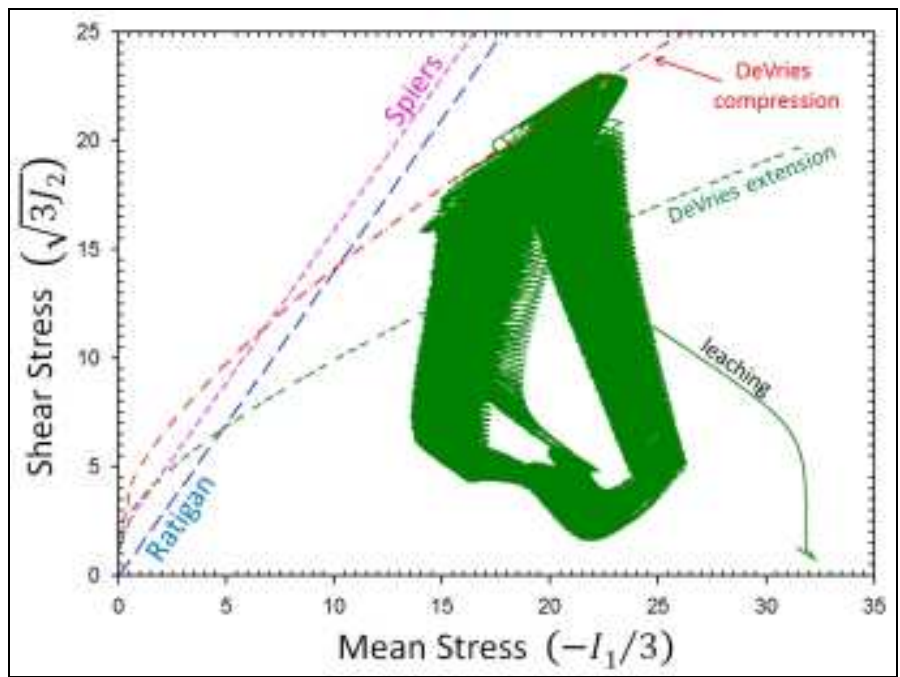

Figure 19.Scenario \#2 - Evolution of the state of stress in the invariants plane.

\section{CONCLUSIONS}

Thermal and mechanical computations of gas storage caverns submitted to fast pressure changes or high frequency cycles require refined grids and small time-steps. Rules of thump are suggested. Closed-form solutions, allowing for comparison with numerical computations, are provided. It is proved that these rules must be taken into account accurate numerical computations are needed.

\section{ACKNOWLEDGEMENTS}

This study was partially supported by ANR (French National Research Agency) in the frame of SACRE, a cooperative research program gathering Electricité de France, Ecole Polytechnique, Geostock, PROMES and L2EP.

\section{REFERENCES}

ATG. 1986. Manuel pour le transport et la distribution du gaz. Titre XIII - Stockages souterrains de gaz. Association Technique de l'Industrie du Gaz en France.

Bérest P., Bergues J., Brouard B., Durup J.G. \& Guerber B. 2001. A salt cavern abandonment test. Int. J. Rock Mech. \& Mining Sci., 38:357-368.

Brouard B., Karimi-Jafari M., Bérest P. \& Frangi A. 2006. Using LOCAS Software to Better Understand the Behavior of Salt Caverns. Proc. SMRI Spring Meeting, Brussels, Belgium, 273-288.

Brouard B., Bérest P. \& Karimi-Jafari M. 2007. Onset of tensile effective stresses in gas storage caverns. Proc. SMRI Fall Meeting, Halifax, Canada, 119-136.

Crotogino F., Mohmeyer K.U. \& Scharf R. 2001. Huntorf CAES: More than 20 years of successful operation. Proc. SMRI Spring Meeting, Basel, Switzerland, 351-362.

DeVries K.L. 2006. Geomechanical Analyses to Determine the Onset of Dilation around Natural Gas Storage Caverns in Bedded Salt. Proc. SMRI Spring Meeting, Brussels, 131150.

Lestringant C., Bérest P. \& Brouard B. 2010.Thermomechanical effects in compressed air storage (CAES). Proc. SMRI Fall Meeting, Leipzig, Germany, 29-44.

Munson D.E. \& Dawson P.R. 1984. Salt constitutive modeling using mechanism maps. In Proceedings of First Conference on the Mechanical Behavior of Salt. Clausthal-Zellerfeld, Germany: Transactions of Technical Publishers, 717-737.

Munson D.E. 1999. Correlation of creep behavior of domal salts. SMRI Spring Meeting, Las Vegas, 3-28.

Ratigan J. L., Van Sambeek L. L., DeVries K. L. \& Nieland J. D. 1991. The influence of seal design on the development of disturbed rock zone in the WIPP alcove seal tests, Rep. RSI-0400, RE/SPEC Inc., Rapid City, S. D.

Spiers C.J., Peach C.J., Brzesowsky R.H., Schutjens P.M., Liezenberg J.L. \& Zwart H.J. 1988. Long term rheological and transport properties of dry and wet salt rocks. EUR 11848, prepared for Commission of the European Communities, by University of Utrecht, Utrecht, The Netherlands. 